\title{
Perceived vulnerability to disease: adaptation and validation of the PVD-br
}

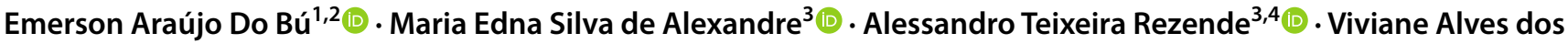 \\ Santos Bezerra ${ }^{3}$ (1)
}

Accepted: 19 October 2021

(c) The Author(s), under exclusive licence to Springer Science+Business Media, LLC, part of Springer Nature 2021

\begin{abstract}
Perceived vulnerability to disease is characterized by the extent to which individuals perceive themselves to be susceptible to contracting infectious diseases, as well as by the emotional discomfort that results from assessing the risk of getting contaminated by pathogens. The PVD self-report scale, which measures this construct, is widely used internationally. However, it has not yet been adapted for Brazil. To address this gap, we adapted and validated the PVD scale for the Brazilian context (PVD-br) in four studies. Study $1(N=39)$ addressed translation, expert validation, and assessment of the comprehensibility of the scale's items. Study $2(N=200)$ showed that the items were organized into two correlated factors and tested the scale's items quality using the Item Response Theory. Study $3(N=201)$ confirmed the bifactorial structure and examined the invariance of PVD-br for men and women, while Study 4 analyzed the convergent $(N=432)$ and discriminant $(N=181)$ validity of the instrument. Results indicate strong evidence of content, factorial, and criterion validity.
\end{abstract}

Keywords Perceived vulnerability to disease $\cdot$ Validation $\cdot$ Adaptation $\cdot$ Scale

Infectious diseases have represented a great threat to humanity's well-being and its existence. It is estimated that such diseases, caused by microorganisms such as viruses, bacteria, protozoa, and fungi were to blame for decimating more human lives than all wars, non-infectious diseases, and natural disasters (Inhorn \& Brown, 1990). Due to these diseases' devastating capacity, the development of research that seeks to comprehend their biological, social, economic, and psychological implications has become commonplace (Segurado et al., 2016). Within this framework, studies regarding the population's perceived vulnerability to disease

Emerson Araújo Do Bú

emerson.bu@campus.ul.pt

1 Institute of Social Sciences, University of Lisbon, Av. Professor Aníbal Bettencourt, nº 9, Entre Campos, 1600189 Lisbon, Portugal

2 Faculty of Psychology, University of Lisbon, Alameda da Universidade, 1649013 Lisbon, Portugal

3 Federal University of Paraíba, Via Expressa Padre Zé Conj. Pres. Castelo Branco III, 58033455, João Pessoa, Paraíba, Brazil

4 Faculdade de Integração do Sertão, Rua João Luiz de Melo, $\mathrm{n}^{\circ}$ 2110, Serra Talhada, Pernambuco, Brazil are important to comprehend social behaviors that facilitate the contraction of infecto-contagious diseases (Duncan et al., 2009; Park et al., 2013).

Perceived vulnerability to disease has been studied in relation to people's disgust sensitivity (Olatunji et al., 2008), attitudes toward disease (Ferguson \& Daniel, 1995), hypochondria (Kellner, 1986), anxiety (Salkovskis et al., 2002), socio-sexual orientations (Simpson \& Gangestad, 1991), and beliefs about a dangerous world (Altemeyer, 1988). Previous research also shows associations between the construct and lower levels of friendship with disabled people (Park et al., 2003), avoidance behaviors toward obese people (Park et al., 2007), negative attitudes against immigrants (Faulkner et al., 2004), ideological positioning (Alexandre et al., 2020; Green et al. 2010), and personality traits (Alexandre et al., 2020). In this context, "perceived vulnerability to disease works as an adaptive strategy which explains why individuals perceived as a source of contagion are avoided" (Díaz et al., 2016, p. 42).

Aiming to resolve the limitations of previous instruments used to assess the perceived vulnerability to disease (e.g., disgust sensitivity scales and hypochondria and healthrelated anxiety measures; Haidt et al., 1994; Olatunji et al., 2008; Pilowsky, 1967), the construct has been assessed through the Perceived Vulnerability to Disease scale (PVD; 
Duncan et al., 2009), which contains 15 items distributed across two dimensions. The first dimension, denominated as Perceived Infectability (PI), includes 7 items that assess beliefs related to immunological functioning and the perceived susceptibility to getting infectious diseases. The second one, called Germ Aversion (GA), includes 8 items responsible for assessing aversive affective reactions to situations in which there is a high probability of pathogen transmission. It is a self-report instrument that has acceptable indices of internal consistency, so it is able to reliably assess individual differences in terms of perceived vulnerability to diseases.

In the original validation studies of the instrument, Duncan et al. (2009) showed that the PVD was related to disgust sensitivity as well as illness attitudes. However, the authors argue that even though there is a relationship between disgust sensitivity and PVD, they are different, as the former relates to a set of circumstances that tend to trigger disgust, while the latter has to do with how much people see themselves as vulnerable to certain diseases, as well as the emotional distress that this risk assessment causes (Duncan et al., 2009). Furthermore, attitudes toward illness should differ from PVD, as the former refers to concerns, behaviors, beliefs, and general feelings about the possibility of becoming ill, whereas PVD specifically assesses beliefs about susceptibility to infectious diseases (Duncan et al., 2009; Stewart and Watt, 2000). Although Duncan et al. (2009) did not test the temporal stability of the construct in previous studies, Díaz et al. (2016) demonstrated high temporal stability (through test-retest analysis) when conducting adaptation and validation studies of the scale for the Spanish context.

Despite the wide use of this measure at an international level, the scale still needs to be adapted for the Brazilian context, even though it has already been used by Alexandre et al. (2020) to verify its predictive effect on the concern of getting COVID-19. Also, considering that previous research has identified gender differences in PVD scores (Coninck et al., 2020; Díaz et al., 2016; Duncan et al., 2009), it is important to provide evidence for the configurational, metric, and scalar invariance of the instrument and to indicate whether it is an equivalent measure for men and women. Considering the need to address this gap, in this research program, we aimed to present evidence of the validity of the Perceived Vulnerability to Disease scale in the Brazilian context (PVD-br).

\section{Overview of the Present Research}

To propose a cross-cultural adaptation and validation of the Perceived Vulnerability to Disease scale (PVD), we carried out four studies in Brazil to demonstrate the evidence of the validity of the PVD-br. In the first study, we addressed translation, expert validation, and assessment of the comprehensibility of the scale items. In the second and the third studies, we sought validity and reliability evidence based on the internal structure of the measure through exploratory and confirmatory factorial analyses. Also, in the third study, a multi-group factorial analysis was used to provide evidence for the configurational, metric, and scalar invariance of the instrument to measure the PVD expression for men and women. Finally, in the fourth study, we aimed to gather validity evidence based on the relationships between the PVD-br and other measures. Specifically, we carried out convergent and discriminant analyses of the PVD-br with measures of disgust sensitivity, illness attitudes, social desirability and biological racism. The studies' procedures were approved by a Research Ethics Committee as required by the Brazilian National Health Council, and to make part of the studies' samples, participants should agree to the Informed Consent Form, where information regarding the objectives of the investigations and how to contact the responsible researcher was available. Datasets and supplemental material used in this research program can be accessed at the OSF repository platform: https://osf.io/6t3ds.

\section{Study 1. Content Validity of the PVD-Br}

We aimed to adapt the PVD items for the Brazilian context and explore the scale's content validity by conducting an expert-rater analysis and an initial pre-test to evaluate the comprehensibility of the items in a community sample (the target population of PVD-br). To do this, we followed two sequential steps: first, we translated the PVD items to Brazilian Portuguese; then, we conducted an evaluation to ensure translation precision, accuracy, and clarity (Study 1a), as well as a pre-test of the comprehensibility of the PVD-br items (Study 1b).

\section{Study 1a}

\section{Method}

\section{Participants}

Four Brazilian psychologists, two men and two women, aged between 24 and $30(M=27.0 ; S D=2.94)$, were invited to be the raters of PVD-br. They were chosen due to their résumés, available on the Lattes Platform, which demonstrate their expertise in Portuguese and English and their research interests linked to healthcare issues. 


\section{Instrument and Procedure for Data Collection}

First, the authors translated from English to Portuguese the 15 items of the PVD scale (Duncan et al., 2009). Then, the items in Portuguese were back-translated to verify whether they were equivalent to the original scale and adequate to the Brazilian context by a native English speaker fluent in Brazilian Portuguese. Items in Brazilian Portuguese and English are available to be consulted at the OSF platform. Finally, an online form with questions regarding (a) translation precision (precise translation of the PVD's items to Portuguese); (b) accuracy (adequate operationalization of the construct); and (c) clarity (clear comprehension by all levels of the target population) of the items was applied with four Brazilian Psychologists that had expertise in Portuguese and English and have research interests linked to healthcare issues. These raters were invited via email with a link to rate the PVD-br items on a 4-point scale ( $1=$ totally inadequate; $2=$ inadequate $3=$ adequate; $4=$ totally adequate). Items with mean scores above three were considered precise in translation, accuracy, and clarity.

\section{Data Analysis Procedure}

Translation precision, accuracy, and clarity of the items were analyzed through the content validity coefficient (CVC), which assesses inter-raters' agreement among judges (Aiken, 1980). More specifically, we calculated the CVC for content expert's judgment $(\mathrm{CVCj})$, for each item (CVCi), and for the total scale ( $\mathrm{CVCt}$ ), using $\mathrm{CVC}$ values $\geq .80$ as the criterion for content validity (Aiken, 1985).

\section{Results}

Results indicate excellent inter-rater agreement regarding precision of translation $(\mathrm{CVCt}=.99)$, accuracy $(\mathrm{CVCt}=.98)$, and clarity $(\mathrm{CVCt}=.99)$ of items (see supplementary material for detailed analysis). All mean scores for these domains were above 3 , thus considered by the judges as adequate or completely adequate (Alexandre \& Coluci, 2011).

\section{Study 1 b}

\section{Method}

\section{Participants}

Thirty-five Brazilians (10 people with high school diplomas, 10 undergraduates, and 15 graduate students) participated in this study. The participants' ages ranged from 19 to 75 years $(M=31.00 ; S D=11.59)$, the majority being female $(77.1 \%)$. This sample size was established following the specialized literature on the development and adaptation of the measure's items (DeVellis, 2016).

\section{Instrument}

We used an online questionnaire for evaluating the wording comprehensibility of the 15 PVD-br's items. Participants were asked to answer, on a scale from 1 (not at all) to 5 (totally), how much they perceived each item as being written in an understandable and clear way. Also, they could suggest modifications to make the sentences more straightforward and understandable.

\section{Data Collection and Analytical Procedures}

Data were collected online using the Qualtrics platform. The mean of item clarity (could vary from 1 to 5) was calculated and used to determine the comprehension and face validity of each item (Dimitrov, 2012; Streiner et al., 2015). Student $\mathrm{t}$-tests were used to test whether the calculated means differed from the scale's mid-point (3.0).

\section{Results}

When it comes to the wording comprehensibility of the PVD-br's items, none were corrected or removed. Moreover, they all had mean scores above 4.0 (means varied from 4.02 - item 1 - to 4.85 - item 1). Student t-tests revealed that all of these means were significantly different $(p=.001)$ from the average point in the scale (3.0), indicating that the items were clear and understandable to the target population of this study (Dimitrov, 2012; Streiner and Kottner, 2014). The detailed analysis from the mean comparisons is available as part of the supplementary material at OSF.

\section{Discussion}

Results from this study showed preliminary evidence of the content validity of the PVD-br. Therefore, the items proved to be clear and straightforward, evincing the individual's perceived vulnerability to disease. However, other forms of validity need to be ensured. To fill such a gap, we developed Study 2 .

\section{Study 2. Evidence of Factorial Validity and Internal Consistency for the PVD-Br}

In Study 2 we aimed to gather preliminary evidence of factorial validity and internal consistency for the PVD-br. Additionally, we aimed to analyze the scale's items quality through the Item Response Theory (Primi, 2004). 


\section{Method}

\section{Participants}

Two hundred and twenty-one Brazilians were invited to take part in a study of perceived vulnerability to disease. However, twenty participants did not reach the end of the questionnaire and were excluded. Our final sample had two hundred and one participants with ages averaging 27 years $(S D=9.21$; varying between 18 and 62 years). The majority indicated that they were females $(76 \%)$, residing in the Northeast of the country $(91.1 \%)$ and having an income of 3 to 4 minimum wages (31.8\%). $49.2 \%$ were white and $56.6 \%$ had finished undergraduate courses. They were selected using non-probabilistic sampling techniques, considering as inclusion criteria being of an age equal to or over 18 and agreeing to voluntarily participate in the study. We defined this sample size using as a minimum criterion ten participants per scale item (Nunnally, 1978).

\section{Instruments and Data Collection Procedure}

Participants answered a questionnaire with socio-demographic questions (e.g., age, income, and sex) and the PVD-br in February of 2020. PVD-br items were randomly presented to participants and answered on a 7-point scale ranging from $1=$ totally disagree to $7=$ totally agree. Data collection was carried out online with the use of the Qualtrics platform. Participants were invited to take part in the study at social networks platforms, such as Facebook, WhatsApp, and Instagram. Initially, after accessing the link, participants received information regarding the goals of the study, the anonymity of their participation, and the possibility of giving up on the research which would not lead to any negative consequences. Only the participants who agreed with the Free Research Informed Consent Form could continue answering the questionnaire. On average, participants spent $8 \mathrm{~min}$ answering the questionnaire.

\section{Data Analysis Procedure}

Data analysis was performed using IBM® SPSS ${ }^{\circledR}$ (version 26) and the R-Studio software. Descriptive statistics were calculated to characterize the participants in the study, and exploratory factor analysis (EFA) was conducted to determine the factorial structure of the measure. First, KMO criterion and Barlett's Sphericity Test were used to assess the suitability of the data for conducting EFA. To determine the number of factors in the PVD-br, we used both classical statistical and theoretical criteria related to the definition of PVD. For the statistical criteria, we referred to the Kaiser criterion, which indicates the extraction of factors that have an eigenvalue of 1 or more; the Cattell criterion, which defends the factorial structure with the number of dimensions equal to the number of points over the inflection point of the scree plot; and the Parallel Analysis, which proposes the extraction of the factors which have eigenvalues greater than those extracted from the random data, assuming that they share the same parameters with the database (Damásio \& Borsa, 2017). Moving on to the theoretical aspects of defining the PVD construct, the premise put forward by Duncan et al. (2009) that there are two dimensions in this latent construct (i.e., Perceived Infectability and Germ Aversion) was used as a starting point. We assessed the internal consistency of the measure using the Composite Reliability formula (CR; Raykov, 1997) performed with the Composite Reliability Calculator (Colwell, 2016) and the average inter-item correlation $\left(r_{\mathrm{i} . \mathrm{j}}\right)$ to assess the homogeneity of the instrument's dimension. Additionally, we also calculated Cronbach's alpha to compare the internal consistency of the PVD-br with previous studies ( $\alpha$; Cronbach, 1951). To further analyze the quality of the items, we used the Item Response Theory (IRT). Specifically, analyses of the parameters a (discrimination) and b (difficulty), and the items' characteristic curves and their information were conducted using the model for politomic items of Gradual Responses by

Samejima (1969). Due to the low expression of missing values (1\%), listwise deletion was performed (Cheema, 2014; Jakobsen et al., 2017).

\section{Results}

\section{Exploratory Factorial Analysis}

First, we analyzed the data factorability and the sample's adequacy measurement through the KMO criterion, and the Barlett's Sphericity Test, calculated from the anti-image correlation matrix. The data presented a variance proportion due to common factors that correlated with each other $\left[\mathrm{KMO}=.71 ; \chi^{2}(105)=678.801, p=.001\right]$. Therefore, they were suitable for conducting EFA. When it comes to the PVD-br factors, we found that according to the Kaiser criterion four dimensions could be extracted (eigenvalues ranged from 3.22 to 1.11 ) which together explained $55.20 \%$ of the total variance. The Cattel criterion also showed the presence of four factors. To further analyze the number of factors in the scale, we used the parallel analysis (Horn, 1965) as it is considered a more robust criterion (Dobriban and Owen, 2019). Based on the parameters of the database (201 participants and 15 variables), the parallel analysis with 1000 simulations showed the appropriateness of retaining three dimensions, which together explained $47.77 \%$ of the total variance. 
Considering the discrepancy between the exposed criteria and their results, we followed the theoretical approach and procedures advocated by Duncan et al. (2009) in the original validation of the PVD; in which it is defined the perceived vulnerability to diseases as the bearer of two dimensions. Accordingly, we submitted the 15 items from the PVD-br one more time to the exploratory factorial analysis using the principal axis factoring method, setting the extraction of two dimensions (oblimin rotation) (Duncan et al., 2009). We verified that these two factors explained $36.4 \%$ of the total variance. We consider an adequate loading factor (h), one equal to or greater than .30 to retain the item on the scale (Pasquali, 2012), leading to the exclusion of items 11 $(\mathrm{h}=.11)$ and $12(\mathrm{~h}=-.20)$. These results are summarized in Table 1; which shows the number of items, factorial loads, and indices of internal consistency for each dimension.

As shown in Table 1, the Perceived Infectability dimension (first factor) had an eigenvalue of 3.22, which explained $21.4 \%$ of the total variance. The six items had factorial loadings ranging from .32 (Item 2. If an illness is 'going around', I will get it) to .81 (Item 8 . In general, I am very susceptible to colds, flu, and other infectious diseases). This dimension refers to beliefs about immunological functioning and personal susceptibility to getting infectious diseases. The internal consistency of this factor was checked by analyzing Composite Reliability (CR) and Cronbach's alpha $(\alpha)$. The $\mathrm{CR}$ was .75, the average inter-items correlation $\left(\mathrm{r}_{\mathrm{i} . \mathrm{i}}\right)$ was .26 , and the $\alpha$ was .74.

The second factor, Germ Aversion, had an eigenvalue of 2.23 and explained $14.9 \%$ of the total variance. The factorial loadings of its six items varied from .41 (item 9. I dislike wearing used clothes because you don't know what the last person who wore them was like) to .69 (item 7. I prefer to wash my hands pretty soon after shaking someone's hand). The current dimension includes items that assess aversive affective reactions to situations that have a high likelihood of disease transmission. It presented $\mathrm{CR}=.70 ; \mathrm{r}_{\mathrm{i}, \mathrm{i}}=.26$; $\alpha=.60$.

\section{IRT Analysis}

The results showed that items 11 (i.e., My hands do not feel dirty after touching money. Reversed and in the Germ Aversion factor) and 12 (i.e., I am unlikely to catch a cold, flu, or other illness, even if it is going around. Reversed and in the Perceived Infectability factor) had low discrimination scores compared to the other items. In addition, both items displayed low information, i.e., low precision in estimating

Table 1 Factorial structure of the PVD-br $(\mathrm{N}=201)$

\begin{tabular}{|c|c|c|c|}
\hline Items & $\begin{array}{l}\text { Perceived } \\
\text { Infectability }\end{array}$ & \multicolumn{2}{|l|}{ Aversion } \\
\hline 8 - In general, I am very susceptible to colds, flu, and other infectious diseases. & .81 & .15 & .62 \\
\hline 10 - I am more likely than the people around me to catch an infectious disease. & .72 & .10 & .56 \\
\hline 6 - I have a history of susceptibility to infectious diseases. & .69 & -.01 & .37 \\
\hline 5 - My past experiences make me believe I am not likely to get sick even when my friends are sick. ${ }^{(R)}$ & .46 & .21 & .32 \\
\hline 14 - My immune system protects me from most illnesses that other people get. ${ }^{(\mathrm{R})}$ & .44 & .19 & .29 \\
\hline 2 - If an illness is 'going around', I will get it. & .32 & .28 & .23 \\
\hline \multicolumn{2}{|c|}{12 - I am unlikely to catch a cold, flu, or other illness, even if it is going around. ${ }^{(\mathrm{R})}-.20$} & -.14 & .02 \\
\hline \multicolumn{2}{|c|}{11 - My hands do not feel dirty after touching money. ${ }^{(\mathrm{R})}-.11$} & -.03 & .04 \\
\hline 7 - I prefer to wash my hands pretty soon after shaking someone's hand. & .17 & .69 & .37 \\
\hline 4 - I don't like to write with a pencil someone else has obviously chewed on. & .18 & .60 & .32 \\
\hline 15 - I avoid using public telephones because of the risk that I may catch something from the previous user. & .07 & .49 & .36 \\
\hline 13 - It does not make me anxious to be around sick people. ${ }^{(\mathrm{R})}$ & .26 & .44 & .27 \\
\hline 3 - I am comfortable sharing a water bottle with a friend. ${ }^{(R)}$ & .13 & .43 & .16 \\
\hline 1- It really bothers me when people sneeze without covering their mouths & .12 & .42 & .21 \\
\hline 9 - I dislike wearing used clothes because you don't know what the last person who wore them was like. & .07 & .41 & .29 \\
\hline Eigenvalue & 3.22 & 2.23 & \\
\hline$\%$ of variance & 21.4 & 14.9 & \\
\hline Composite Reliability & .75 & .70 & \\
\hline \multicolumn{2}{|c|}{ Cronbach's alpha .74} & .60 & \\
\hline Factor Average & 3.26 & 4.24 & \\
\hline$S D$ & .85 & .81 & \\
\hline
\end{tabular}

Items 11 and 12 were considered not adequate because of their loading factor; loading factor in bold indicates to which factor the item is linked; (R) $=$ Inversed items; $\mathrm{h}^{2}=$ communality; $\mathrm{SD}=$ Standard Deviation 
latent traits (Table 2). Characteristic curves for the items and the item's information for the two PVD-br factors, available as supplementary material, also revealed that these items had an inappropriate pattern of response probabilities compared to the other items (i.e., higher probability of responses in category 1 - I totally disagree). In other words, most of the participants were more probable to believe they were more susceptible to colds, flu and other illness, and more concerned in relation to cleaning hands after touching money.

\section{Discussion}

The results of this study provided preliminary evidence of the factorial validity of the PVD-br. Based on the same procedures used by Duncan et al. (2009), we observed that the bifactorial structure showed adequate internal consistency indicators, with composite reliabilities above .70 (Viladrich et al., 2017) and average inter-items higher than the recommended values (Silber et al., 2018; Valentini \& Damásio, 2016). We highlight that in the PVD validation study by Duncan et al. (2009), the two factors of the scale explained $46.3 \%$ of the total variance, i.e., a higher explained data variance than in the present study (36.4\%). The internal consistency of the factors in the validation study of the original scale was also better $(\alpha=.87$ for the factor Perceived Infectability; $\alpha=.74$ for the factor Germ Aversion) compared to the current study ( $\alpha=.74$ and $\alpha=.60$, respectively). However, we note that Duncan et al. (2009) had a sample of 1539 participants in such a study.
Nonetheless, although other studies that used the two PVD subscales (Murray et al., 2013; Makhanova et al., 2015) obtained good internal consistency for both factors, the studies by Díaz et al. (2016), Miller and Maner (2012), Prokop and Fančovičová (2013), and Wu and Chang (2012) did not find satisfactory reliability for the subscale Germ Aversion, with Cronbach's alphas ranging from .55 to .61. Díaz et al. (2016) argue that the wide range of different behaviors (e.g., sharing a bottle of water, touching money, using a pencil, shaking hands) may explain the lower internal consistency of this factor, given that they are general behaviors without reference to the infectious disease context, as is the case for the Perceived Infectability dimension (i.e., the context of colds or infectious diseases in general), because alpha can decline in the face of different behaviors without a common contextualization framework (McCrae et al., 2010). We used composite reliability that considers each item's factor loading, and we obtained adequate internal consistency results.

Even though the results found in this study indicated good internal consistency with the 13-item structure, items 11 and 12, whose factor loadings were low, will be retested in subsequent studies. Given that the excluded items relate to the transmission of colds and flu, as well as concerns about dirty hands after touching money, we believe that the Covid-19 pandemic may have influenced participants' responses, leading them to agree with the items more frequently. We argue this in light of previous studies showing that excessive anxiety and fear of contracting Covid-19 or thoughts of death itself increased during the pandemic (Pakpour \& Griffiths, 2020; Silva et al., 2020).
Table 2 PVD-br IRT parameters

\begin{tabular}{lllllllll}
\hline & $\mathrm{a}$ & $\mathrm{b}_{1}$ & $\mathrm{~b}_{2}$ & $\mathrm{~b}_{3}$ & $\mathrm{~b}_{4}$ & $\mathrm{~b}_{5}$ & $\mathrm{~b}_{6}$ & $\mathrm{I}(-3 ;+3)$ \\
\hline $\mathrm{PI}$ & & & & & & & & \\
2 & .61 & -4.08 & -2.60 & -1.02 & .80 & 2.84 & 4.30 & .72 \\
5 & -.82 & .89 & -.75 & -1.57 & -2.62 & -4.34 & -6.74 & 1.14 \\
6 & 2.00 & -1.15 & -.01 & .33 & .97 & 1.55 & 2.51 & 5.88 \\
8 & 3.84 & -1.28 & -.38 & -.02 & .34 & .83 & 1.50 & 15.31 \\
10 & 2.30 & -1.19 & -.08 & .37 & .98 & 1.37 & 2.26 & 7.38 \\
12 & -.35 & 1.23 & -2.91 & -4.61 & -7.03 & -8.16 & -15.02 & .22 \\
14 & -.60 & 3.16 & .72 & -.39 & -1.78 & -4.11 & -8.96 & .69 \\
$\mathrm{GA}$ & & & & & & & & \\
1 & .93 & -3.96 & -3.79 & -3.30 & -2.43 & -1.35 & -.08 & 1.23 \\
3 & -.81 & 1.62 & .00 & -.72 & -1.37 & -2.68 & -3.84 & 1.17 \\
4 & 1.83 & -2.39 & -1.52 & -.88 & -.43 & -.23 & .88 & 4.76 \\
7 & 1.71 & -2.34 & -1.30 & -.65 & -.01 & .64 & 1.82 & 4.87 \\
9 & 1.00 & -1.57 & -.12 & .50 & .70 & 1.11 & 2.58 & 1.72 \\
11 & -.30 & -1.42 & -4.17 & -5.58 & -6.82 & -7.15 & -8.79 & .13 \\
13 & -.86 & 2.02 & .61 & -.29 & -1.08 & -1.89 & -3.39 & 1.36 \\
15 & 1.24 & -2.32 & -1.13 & -.59 & .30 & .66 & 1.79 & 2.66 \\
\hline
\end{tabular}

$\mathrm{PI}=$ Perceived Infectability; GA=Germ Aversion; $\mathrm{a}=$ discrimination; $\mathrm{b} 1$ to $\mathrm{b} 6=$ item difficulties by response category; $I=$ item information in the limit of theta -3 and 3 
Also, public campaigns on the need to constantly use alcohol and wash hands to avoid transmitting the new coronavirus may have led participants to perceive their hands as dirtier after using money, considering that it is constantly in motion in society and could be a potential transmission route for the virus. Therefore, to analyze whether the results described in this study can be replicated with an independent sample, we designed Study 3 to examine the instrument's bifactorial fit and compare it to other possible structures.

\section{Study 3. Confirmatory Factorial Analysis of the PVD-Br}

We aimed in this study to gather additional empirical evidence of the PVD-br's factorial validity and reliability for an independent sample. We sought to test, through the confirmatory factorial analysis, the replicability of the factorial structure that was obtained in Study 2 and compare it to alternative factorial models (unifactorial, trifactorial, and tetrafactorial). Additionally, we aimed to analyze the psychometric equivalence of the PVD-br for men and women. Therefore, we conducted a multi-group confirmatory factor analysis to examine the configurational, metric, and scalar invariance of the PVD-br for these groups.

\section{Method}

\section{Participants}

Two hundred and twelve Brazilians were invited to participate in a study of perceived vulnerability to disease. Nevertheless, 12 did not reach the end of the questionnaire and were excluded. Our final sample included 200 participants. Their ages varied from 18 to 63 years $(M=28.97$; $S D=8.59)$. They were predominantly female $(67 \%)$, lived in the northeast of the country $(65 \%)$, and had an income of 3 to 4 minimum wages (31\%). They self-reported having white skin (50\%) and had graduate degrees (46.4\%). This was a convenience sample, only participating in the study those who accepted to do so voluntarily. As in Study 2, we defined the sample size using a minimum criterion of ten participants per scale item (Nunnally, 1978).

\section{Instruments and Data Collection Procedure}

We used the same instrument and followed the same data collection procedures as in Study 2. However, data was collected in March 2020.

\section{Data Analysis Procedure}

We used the IBM® SPSS® Statistics (version 25) and JASP (version 0.14.1) software to analyze the data collected. Using the former, descriptive statistics were calculated; with the latter, it was possible to ascertain whether the bifactorial model was the most adequate for the PVD-br. Accordingly, the bifactorial structure was compared with three alternative models: unifactorial, trifactorial, and tetrafactorial. The analysis was implemented utilizing the Robust Diagonally Weighted Least Squares (RDWLS) estimation method, which is appropriate for categorical data (DiStefano \& Morgan, 2014; Li, 2016). The following adjustment indicators were considered (Brown, 2015): (a) chi-square ratio by degrees of freedom $\left(\chi^{2} / \mathrm{gl}\right)$, admitting as recommended values those that range from 2 to 3 , values up to 5 still being considered acceptable; (b) Comparative Fit Index (CFI) and Tucker-Lewis Index (TLI), whose values are acceptable if equal to or above .90; (c) Standardized Root Mean Square Residual (SRMR), the model is regarded as adjusted when its value is under .08, and Root Mean Square Error Approximation (RMSEA), whose recommended values range between .05 and .08 , values up to. 10 still being considered acceptable. Besides these indicators, aiming to compare the competing models that were tested, the Bayesian Information Criterion (BIC) and the Akaike Information Criterion (AIC) were employed. Lower BIC and AIC values reflect a better-adjusted model (Garson, 2015). As in Study 2, the internal consistency of the instrument was measured through the composite reliability (CR; Raykov, 1997) and Cronbach's alpha (Cronbach, 1951).

Moreover, a multi-group factorial analysis was performed to examine the invariance of PVD-br for men and women. The analysis was conducted also using the RDWLS estimation method. Multi-group factor analysis assessed the invariance of the measure in three models: configurational invariance (unconstrained model fit for each group), metric invariance (all factor loadings constrained to be equal across groups) and scalar invariance (all factor loadings and intercepts were equal across groups) (Byrne, 2012; Carapito et al., 2020; Cheung \& Rensvold, 2002). Measurement invariance was assessed using the CFI difference test. The decrease in CFI indices $(\Delta \mathrm{CFI}>$ $.01)$ when parameters are adjusted means that the invariance of the measure cannot be accepted (Cheung \& Rensvold, 2002). We used the Listwise deletion to handle the missing values (Cheema, 2014; Jakobsen et al., 2017).

\section{Results}

\section{Confirmatory Factorial Analysis}

Although we did not obtain adequate parameters for retaining items 11 and 12 of the scale in the EFA (Study 2), we 
first retested the bifactorial model proposed by Duncan et al. (2009) with the 15 items of the scale. The factor loadings of these items remained low (see supplementary material for a detailed analysis). Therefore, we retained the 13-item structure found in Study 2 and compared it with other alternative models. As alternative models, we adopted the unifactorial model, which is widely reported in the literature (Alexandre et al., 2020; Stangier et al., 2021; Yamada et al., 2020), as well as the trifactorial and tetrafactorial models, as suggested by the parallel analysis and the Kaiser and Cattel criteria, respectively (Table 3).

According to the results presented in Table 2, the unifactorial and trifactorial models must be discarded, as its adjustment indicators were inadequate $(\mathrm{CFI}=.75$; $\mathrm{TLI}=.71$ and $\mathrm{CFI}=.89 ; \mathrm{TLI}=.86$, respectively). Also, it is possible to observe that, even though the tetrafactorial model presents sound adjustment indices, those that best fit the recommendations given by the literature (Brown, 2015; Byrne, 2016) are from the bifactorial model. This model was more plausible, displaying adequate incremental indices (e.g., $\mathrm{CFI}=.95$ and $\mathrm{TLI}=.94)$ and presenting absolute values that were as recommended $\left(\chi^{2} / \mathrm{df}\right.$ and RMSEA). Moreover, we observed that the tetrafactorial model has two factors with only two items, and when comparing the BIC values, the bifactorial model also stood out. As shown in Fig. 1, all PVD-br items had factorial loadings (lambdas $-\lambda$ ) that were statistically different from zero $(\lambda \neq 0 ; z>1.96 ; p<.05)$. Therefore, the goodness-tofit adjustment indices indicate a bidimensional structure of the PVD-br. Also, the CR calculations for the two measured dimensions were: .70 for Perceived Infectability and .66 for Germ Aversion; and the Cronbach alphas were .69 and .60 for the two factors, respectively.

\section{Multi-Group Confirmatory Analyses of the PVD-Br}

As presented in Table 4, results comply with the configurational, metric and scalar invariance and indicate that PVDbr is an equivalent measure for male and female participants, allowing for comparison between groups.

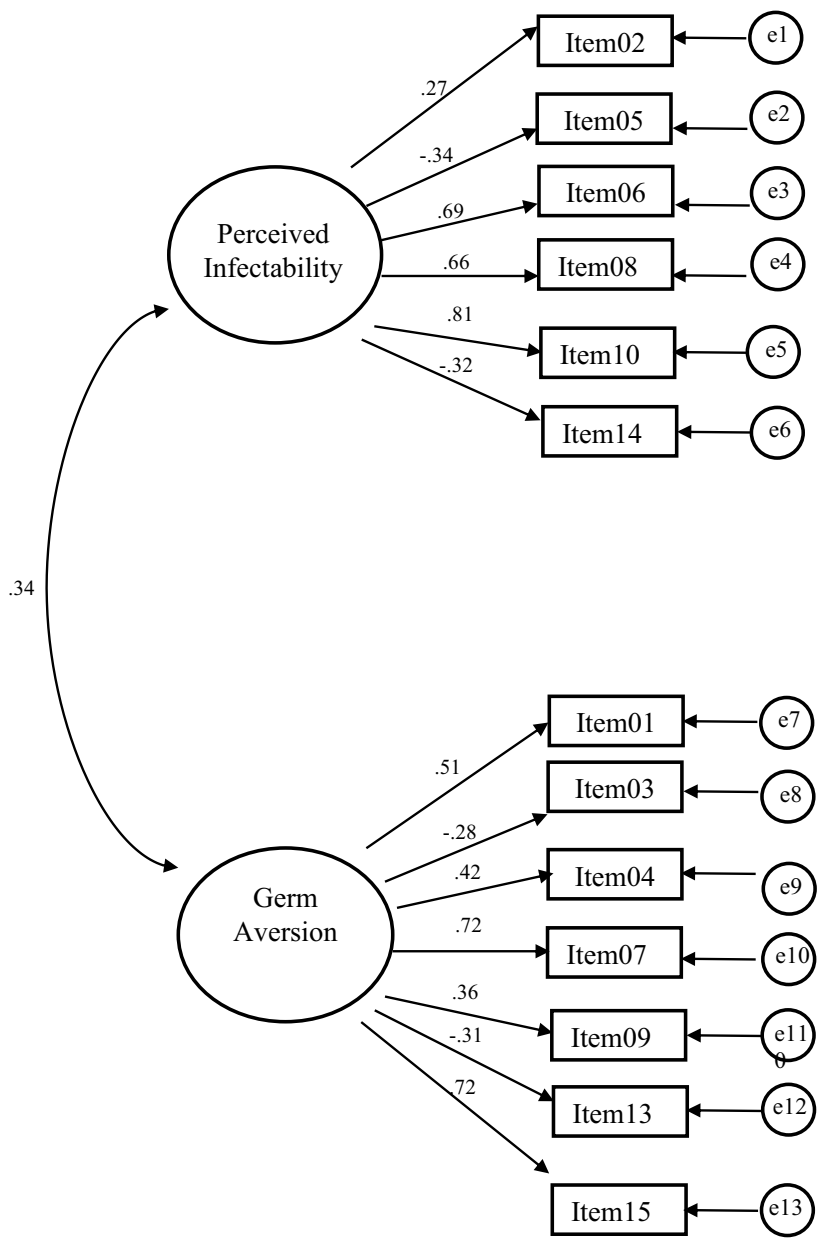

Fig. 1 Bifactorial Structure of the PVD-br

\section{Discussion}

In this study, we aimed to determine the factorial structure of the PVD-br through a confirmatory factorial analysis. We also analyzed the psychometric equivalence of the PVD-br for males and females. This procedure led us to a more robust conclusion about the factorial validity of the
Table 3 Goodness-of-fit statistics for confirmatory factor analysis models of the PVD-br $(\mathrm{N}=200)$

\begin{tabular}{llllllll}
\hline Models & $\chi^{2} / \mathrm{df}$ & CFI & TLI & RMSEA (IC90\%) & SRMR & BIC & AIC \\
\hline $\mathrm{M}_{1}$ & $3.07^{*}$ & .75 & .71 & $.10(.08-.12)$ & .11 & 9860.04 & 9857.58 \\
$\mathrm{M}_{2}$ & $1.37^{*}$ & .95 & .94 & $.04(.01-.06)$ & .07 & 9817.20 & 9729.10 \\
$\mathrm{M}_{3}$ & $1.97^{*}$ & .89 & .86 & $.07(.05-.09)$ & .08 & 9840.75 & 9746.14 \\
$\mathrm{M}_{4}$ & $1.43^{*}$ & .95 & .93 & $.04(.02-.07)$ & .07 & 9820.82 & 9716.41 \\
\hline
\end{tabular}

M1(unidimensional structure), M2 (bifactorial structure), M3 (trifactorial structure) and M4 (tetrafactorial structure). $\mathrm{CFI}=$ comparative fit indices; $\mathrm{TLI}=$ Tucker-Lewis Index; RMSEA = root mean square error of approximation; $\mathrm{SRMR}=$ standardized root mean square residual; $\mathrm{AIC}=$ Akaike Information Criterion; $\mathrm{BIC}=$ Bayesian information criteria $* p<.05$ 
Table 4 Multi-group analyses for the PVD-br

\begin{tabular}{llllll}
\hline & RMSEA (90\% IC) & SRMR & TLI & CFI & $\Delta$ CFI \\
\hline $\begin{array}{l}\text { Configurational } \\
\text { invariance }\end{array}$ & $.014(.000-.053)$ & .090 & .995 & .996 & - \\
Metric invariance & $.017(.000-.053)$ & .094 & .993 & .993 & .003 \\
Scalar invariance & $.026(.000-.056)$ & .092 & .982 & .983 & .010 \\
\hline
\end{tabular}

Note. RMSEA = root mean square error of approximation; $\mathrm{SRMR}=$ standardized root mean square residual; $\mathrm{TLI}=$ Tucker-Lewis Index; $\mathrm{CFI}=$ comparative fit indices; $\Delta \mathrm{CFI}=\mathrm{CFI}$ difference test

previously mentioned measurement and showed how the empirical data fit the proposed theoretical model (Damásio \& Borsa, 2017). We verified that after comparing different models, the bifactorial structure was the one that best fit the data, which is consistent with the results obtained by Duncan et al. (2009) in the original validation of the scale and other adaptations of the measurement to different cultural contexts (Díaz et al., 2016; Fukukawa et al., 2014; Magallares et al., 2017). In addition, we examined the configurational, metric, and scalar invariance of the PVD-br, as several studies have found gender differences in PVD scores (Coninck et al., 2020; Díaz et al., 2016; Duncan et al., 2009). Thus, the present study provided evidence that future studies can compare PVD scores between men and women with the PVD-br. Although the internal structure of the PVD-br has been demonstrated in this and previous studies, new evidence is needed regarding the 13-item version of the instrument's validity with other variables. Therefore, we developed Study 4.

\section{Study 4. Convergent and Discriminant Validity of the PVD-Br}

This study aimed to demonstrate the convergent (4a) and discriminant (4b) validity of the PVD-br in independent samples. Specifically, the bifactorial structure of the instrument was compared with other constructs. For convergent validity, the instrument was hypothesized to positively correlate with disgust sensitivity and illness attitudes, which, as indicated in the original validation of the scale, capture latent traits close to those measured by the PVD-br. Discriminant validity tested the hypothesis that social desirability and racism are not correlated with the PVD-br (AERA; APA; NCME, 2014). That is, a low or null level of correlation is expected (Cohen, 1992).

\section{Study $4 a$}

\section{Method \\ Participants}

Four hundred and thirty-two Brazilians participated in this study. They were aged between 18 and 63 years $(M=28.09 ; S D=8.57)$, mostly female $(69.4 \%)$, residing in the northeast region of Brazil (78.4\%), and had undergraduate degrees (48.8\%). Most participants of the sample had incomes between 3 and 4 minimum wages (32.2\%) or between 1 and 2 minimum wages (29.9\%) and were white (44.0\%). This sample size has a power of .95 to detect a small effect size of $r=.172$ (Cohen, 1992) or higher, with an alpha set at .05 (Zhang \& Yuan, 2018).

\section{Data Collection Procedure and Instruments}

We followed the same data collection procedure used in previous studies. Nevertheless, in addition to randomly presenting the items from the PVD-br, we also counterbalanced the order of the PVD-br, the Illness Attitudes Scale, and the Disgust Sensitivity Scale. The instruments used in this study are described below. Data collection occurred in March 2020.

PVD-Br We used the 13-item version of the PVD-br to measure participants' perceived vulnerability to disease. In this study, its internal consistency indices were: Perceived Infectability $(\mathrm{CR}=.73 ; \alpha=.71)$ and Germ Aversion $(\mathrm{CR}=.68 ; \alpha=.66)$. Analysis of the 15 and 13-item versions of the instrument can be accessed as supplementary analysis at the OSF platform. The one that stood out with the best psychometric parameters was the 13-item version, as shown in previous studies.

Illness Attitudes Scale Participants answered the Illness Attitudes Scale (IAS), developed by Stewart and Watt (2008). This measure contains 27 items that are answered on a 5 -point scale $(1=$ never to $5=$ all the time $)$ subdivided into four factors (Fears, Behaviors, Beliefs, and Effects). In this study, the instrument dimensions' CR and Cronbach alphas were satisfactory (Fears, $\mathrm{CR}=.91$ and $\alpha=.90$; Behaviors, $\mathrm{CR}=.65$ and $\alpha=.64$; Beliefs, $\mathrm{CR}=.69$ and $\alpha=.75$; and Effects, $\mathrm{CR}=.65$ and $\alpha=.68)$, as well as the general instrument $(\mathrm{CR}=.876$ and $\alpha=.88)$.

Disgust Sensitivity Scale - Revised Participants answered the Portuguese adaptation of the Disgust Sensitivity Scale Revised (DS-R; Ferreira-Santos et al., 2011). The instrument 
contains 27 items that are answered on a response scale from 0 (strongly disagree/very false to me) to 4 (strongly agree/ very true about me). It has three dimensions: (1) core/basic disgust; (2) disgust related to the animal nature of human beings; (3) disgust based on contamination. In this study, the CR of these dimensions were: .70, .73, .57, respectively. The general CR of the scale was .863. Cronbach alphas were $.63, .72, .54$. When considering the general scale $\alpha=.82$.

Participants also answered a socio-demographic questionnaire with questions concerning their gender, age, education, and income.

\section{Data Analysis Procedure}

Descriptive statistics were performed to characterize the sample. Bivariate correlations and multiple regression (Enter method) were used to examine independent associations between Perceived Infectability and Germ Aversion with the other instruments. Multicollinearity was also examined using Variable Inflation Factors (VIF) $>10$.

\section{Results}

To test the convergent validity hypothesis of the PVD-br, we analyzed bivariate correlations and multiple regression results, which are presented in the first panel of Table 5. The results showed that the illness attitudes were positively correlated with Perceived Infectability and Germ Aversion. In addition, disgust sensitivity was associated with Perceived Infectability and Germ Aversion. Correlations were low or moderate (Cohen, 1992).

\section{Study $4 b$}

\section{Method}

\section{Participants}

One hundred and eighty-one Brazilians participated in this study. Their ages ranged from 18 to 65 years $(M=31.33$; $S D=10.32)$. They were predominantly female $(59.7 \%)$, brown (48.1\%), resided in northeastern Brazil (85.1\%), and had a university degree (44.8\%). This sample size has the power of .95 to detect the effect size of $r=.263$ or larger, with an alpha set at .05 (Zhang \& Yuan, 2018).

\section{Data Collection Procedure and Instruments}

We followed the same data collection procedure as in Study 4a. However, in addition to the PVD-br, we also used the Social Desirability Scale and the Racial Beliefs Scale. Data collection occurred in August 2021.

PVD-Br The 13-item version of the PVD-br tested in previous studies was used for data collection. Before using this version, as in Study 4a, we analyzed the instrument's
Table 5 Bivariate correlations and multiple regression results concerning convergent and discriminant PVD-br's validity

\begin{tabular}{|c|c|c|c|c|c|}
\hline \multirow[t]{3}{*}{ Convergent Validity } & & & & & \\
\hline & \multicolumn{2}{|l|}{ Perceived Infectability } & \multicolumn{2}{|l|}{ Germ Aversion } & \multirow[b]{2}{*}{ VIF } \\
\hline & $r$ & $\beta$ & $r$ & $\beta$ & \\
\hline Illness Attitudes & \multicolumn{2}{|l|}{$.30 * *$} & \multicolumn{2}{|l|}{$.20 * *$} & \\
\hline Fears & $.24 * *$ & .084 & $.19 * *$ & .000 & 2.60 \\
\hline Behavior & .02 & -.005 & $.13 * *$ & .089 & 1.10 \\
\hline Beliefs & $.29 * *$ & $.196 *$ & $.17 * *$ & .149 & 2.86 \\
\hline Effects & $.25 * *$ & $.118 *$ & .09 & -.064 & 1.47 \\
\hline Disgust Sensitivity & \multicolumn{2}{|l|}{$.12 * *$} & \multicolumn{2}{|l|}{$.26 * *$} & \\
\hline Core Disgust & $.14 * *$ & .036 & $.10 *$ & $.119 *$ & 1.41 \\
\hline Animal Reminder Disgust & $.29 * *$ & $.148 *$ & $.32 * *$ & $.274 * *$ & 1.33 \\
\hline \multirow[t]{2}{*}{ Contamination } & $.10 *$ & $-.147 *$ & $.38 * *$ & $.187 * *$ & 1.44 \\
\hline & \multicolumn{2}{|l|}{$R^{2} \mathbf{a d j}=.127$} & \multicolumn{2}{|l|}{$R^{2} \mathbf{a d j}=.156$} & \\
\hline \multicolumn{6}{|l|}{ Discriminant Validity } \\
\hline & \multicolumn{2}{|l|}{ Perceived Infectability } & \multicolumn{2}{|l|}{ Germ Aversion } & \\
\hline & $r$ & $\boldsymbol{\beta}$ & $r$ & $\boldsymbol{\beta}$ & VIF \\
\hline Social Desirability & .15 & .12 & .02 & .01 & 1.00 \\
\hline \multirow[t]{2}{*}{ Biological Racism } & -.12 & -.12 & -.09 & -.09 & 1.00 \\
\hline & \multicolumn{2}{|l|}{$R^{2} \mathbf{a d j}=.019$} & \multicolumn{2}{|l|}{$R^{2} \operatorname{adj}=.005$} & \\
\hline
\end{tabular}

Multiple regression detailed results are available as supplementary material. VIF $=$ Variable Inflation Factors; $* * p=.001 ; * p=.005$ 
structure. As previous studies have shown, items 11 and 12 still push the worse loading factors one year after the first data collection (see supplementary material for detailed analyses). In this study, the scale displayed $\mathrm{CR}=.68$ and $\alpha=.66$ to its Perceived Infectability dimension and $\mathrm{CR}=.71$ and $\alpha=.66$ to Germ Aversion.

Social Desirability Scale answered the Social Desirability Scale proposed by Crowne and Marlowe (1960). It consists of 20 items (with true or false answers), organized in a unifactorial structure. This scale had $\mathrm{CR}=.67$ and $\alpha=0.67$.

Racial Beliefs Scale Participants answered the 7-item version ( $1=$ totally disagree; $7=$ totally agree $)$ of the Racial Beliefs Scale (RBS) (Vala et al., 2009; Vala et al., 2012, Experiment $3)$. This instrument measures beliefs regarding the biological nature of differences between groups. The RBS showed for this study the internal consistency of $\mathrm{CR}=.74 ; \alpha=.74$. Higher scores in this scale indicate stronger explicit racism.

A socio-demographic questionnaire with questions concerning participants' gender, age, education, and income was also applied.

\section{Data Analysis Procedure}

The analysis procedure was the same as in Study 4a. However, we expected the correlations between the constructs to be nonexistent or null.

\section{Results}

Bivariate correlations and multiple regression results, presented in the second panel of Table 5, showed that the PVDbr factors were not related either to social desirability or racism.

\section{Discussion}

Results from Study 4a revealed that the PVD-br is correlated with the Illness Attitudes and Disgust Sensitivity measures. The low and moderate levels for the correlations found in this study are similar to those identified by Duncan et al. (2009), who defend that despite the similarity of these three constructs, each has its own characteristics that distinguish them from one another (as presented in the previous section of this paper). Three of the four factors of illness attitudes correlated more strongly with Perceived Infectability, while two of the three factors of disgust sensitivity correlated more strongly with Germ Aversion. This can be explained as Perceived Infectability is a cognitive factor about fears, beliefs, and subjective perceptions, whereas Germ Aversion is more related to disgust or discomfort about certain risk behaviors (Díaz et al., 2016). Our findings are also supported by the studies developed by Santisi et al. (2021), who observed positive and significant relationships between a disgust scale and Perceived Infectability, and by the study of Magallares and Morales (2017), who found positive and significant relationships between physical disgust and germ aversion.

Concerning the relationships between PVD-br and social desirability and racism (Study $4 \mathrm{~b}$ ), the results showed no correlation between these constructs. These results confirm previous findings by Duncan et al. (2009) indicating a nonsignificant relationship between Perceived Vulnerability to Disease and social desirability. However, we highlight a study by Díaz et al. (2016) who found non-significant correlations between Perceived Infectability and social desirability, but a positive and significant relationship between the construct and Germ aversion. Furthermore, the PVD scores were not significantly related to biological racism. Thus, our findings support the hypothesis that the PVD-br displays convergent and discriminant validity evidence. These types of validity are important because they offer complementary validity evidence for the construct.

\section{General Discussion}

In four studies, we described the adaptation and validation process of the PVD for the Brazilian context (PVD-br). Specifically, in Study 1, we adapted the items of the scale and showed their content validity. In Study 2, we examined the factorial structure of the scale, whose results showed a parsimonious structure of the two factors measuring Perceived Vulnerability to Disease with high internal reliability. Study 3 confirmed the bifactorial structural adequacy of the PVDbr as the best factorial model and demonstrated the configurational, metric, and scalar invariance of the instrument for measuring PVD scores in men and women. Finally, Study 4 demonstrated the convergent and discriminant validity of the instrument by correlating it with illness attitudes, disgust sensitivity, social desirability, and racism measures. Taken together, the results of these studies showed strong evidence of content, factorial, and criterion validity of the scale for the Brazilian context.

Although the PVD-br is an appropriate option to measure Perceived Vulnerability to Disease in the Brazilian context, the studies have some limitations. First, we point out that the samples were not representative of the entire Brazilian population, as they consisted mainly of college students. Therefore, future studies should attempt to homogenize the samples to verify that the factorial structure of the instrument applies to individuals with low education. It will also be necessary to investigate whether the pandemic context instilled by Covid-19 may have influenced the factorial 
structure of the PVD-br tested in these studies. As discussed in Study 2, it is possible that the perceived contagiousness that was prominent during the data collection period (February/March 2020 and August 2021) could have influenced the data presented. Also, if this pattern of results found in this research program is replicated in other countries where the measure has been validated before, one could argue and investigate whether the Covid-19 pandemic and social norms such as social distancing and hygienic intensity practices have changed how the Perceived Vulnerability to Disease construct is assessed. In addition, although the PVD was found to be a highly stable latent construct over time (Díaz et al., 2016), neither the test-retest reliability of the PVDbr has been analyzed, nor other types of validity based on relationships with external measures, such as concurrent validity (i.e., a high correlation between PVD-br and another measure of the same construct) and predictive validity (i.e., the ability of the scores obtained to predict future behavior through longitudinal studies) (AERA; APA; NCME, 2014). Nevertheless, it will be fundamental to analyze in future studies to what extent the PVD-br is sensitive to experimental manipulations.

Despite the need for such improvements, we verified that the results confirm the related literature when replicating the bifactorial structure of the PVD; moreover, they demonstrate the reliability of the PVD-br when confirming that the instrument measures the latent construct in the Brazilian context for men and women. In addition, we highlight the practical implications of the PVD-br scale, as it is an instrument with multiple uses in different contexts. For example, we highlight its use in a clinical context of psychology that aims to observe differences in how individuals perceive themselves as vulnerable to illnesses and contextualize this impact on their emotions. This is particularly important during a pandemic, such as COVID -19, as the risk of contracting the new coronavirus and developing the disease may make the perceived vulnerability to disease even stronger, which becomes an anxiety-provoking and stressful factor for the individual. Therefore, measuring this perception can provide the psychologist with the proper tools to select an appropriate intervention.

From a more collective perspective, the potential of this scale as a subsidy for the construction of public policies is noteworthy, especially in pandemic states where there is a high risk of contamination by pathogens. Accordingly, noting that the population has different perceptions regarding the perception of vulnerability to infectious diseases may direct the focus of psychoeducational campaigns. Thus, it would be possible to construct public policies that are sensitive to such variations and promote more assertive prophylactic behaviors to prevent and mitigate pathogen transmission. In short, we propose that the PVD-br is a shorter version of the PVD questionnaire that allows the accurate and valid assessment of perceived vulnerability to disease in the Brazilian context.

Author's Contributions We attest that the authors cited participated equally in the conception and revisions that resulted in this paper, that is, a) conception and outline of the work and participation in the discussion of results; b) writing of the manuscript and critical review of its content; c) approval of the final version of the manuscript.

Funding The National Council for Scientific and Technological Development $(\mathrm{CNPq})$; Fundação para a Ciência e a Tecnologia (FCT).

Data availability Datasets and supplemental material used in this research program can be accessed at the OSF repository platform: https://osf.io/6t3ds?.

Code Availability Not applicable.

\section{Declarations}

Ethics Approval Committee for Ethics in Research on Human Beings, number of registry 3.982.598 and Certificate of Presentation for Ethics Appreciation 30.616.720.9.0000.0008.

Consent to Participate Informed consent was obtained from all individual participants included in the study.

Consent for Publication The authors affirm that human research participants provided informed consent for publication of the data collected.

Conflict of Interest The authors declare that there are no conflicts of interest to disclose.

\section{References}

Aiken, L. R. (1980). Content validity and reliability of single items or questionnaires. Educational and Psychological Measurement, 40(4), 955-959. https://doi.org/10.1177/001316448004000419

Aiken, L. R. (1985). Three coefficients for analyzing the reliability, and validity of ratings. Educational and Psychological Measurement, 45(1), 131-142. https://doi.org/10.1177/0013164485451012

Alexandre, M. E. S., Do Bú, E. A., Bezerra, V. A. S., Lima, K. S., Santos, V. M., \& Farias, S. S. C. (2020). Posicionamento Atitudinal, Percepção de Vulnerabilidade e Preocupação em contrair a COVID-19. Arquivos Brasileiros de Psicologia, 72(2), 25-42. https://doi.org/10.36482/1809-5267.arbp2020v72i1p.25-42

Alexandre, N. M. C., \& Coluci, M. Z. O. (2011). Validade de conteúdo nos processos de construção e adaptação de instrumentos de medidas. Ciência \& Saúde Coletiva, 16(7), 3061-3068. https://doi.org/ 10.1590/S1413-81232011000800006

Altemeyer, B. (1988). Enemies of freedom: Understanding right-wing authoritarianism. Jossey-Bass.

American Educational Research Association, American Psychological Association, National Council on Measurement in Education. (2014). Standards for educational and psychological testing. American Psychological Association.

Brown, T. A. (2015). Methodology in the social sciences: Confirmatory factor analysis for applied research (2nd ed.). The Guilford Press. 
Byrne, B. M. (2016). Structural equation modeling with Amos: Basic concepts, applications, and programmimg. (3a Ed.). Routledge.

Byrne, B. M. (2012). Structural equation modeling with Mplus: Basic concepts, applications, and programming. Routledge.

Carapito, C., Ribeiro, M. T., Pereira, A. I., \& Roberto, M. S. (2020). Parenting stress and preschoolers' socio-emotional adjustment: The mediating role of parenting styles in parent-child dyads. Journal of Family Studies, 26(4), 594-610. https://doi.org/10. 1080/13229400.2018.1442737

Cheema, J. R. (2014). A review of missing data handling methods in education research. Review of Educational Research, 84(4), 487-508. https://doi.org/10.3102/0034654314532697

Cheung, G. W., \& Rensvold, R. B. (2002). Evaluating goodness-of-fit indexes for testing measurement invariance. Structural Equation Modeling: A Multidisciplinary Journal, 9(2), 233-255. https:// doi.org/10.1207/S15328007SEM0902_5

Cohen, J. (1992). Statistical power analysis. Current Directions in Psychological Science, 1(3), 98-191. https://doi.org/10.1111/14678721.ep10768783

Colwell, S. R. (2016). The composite reliability calculator. Technical Report. 10.13140/RG.2.1.4298.088.

Coninck, D., d'Haenens, L., \& Matthijs, K. (2020). Perceived vulnerability to disease and attitudes towards public health measures: COVID-19 in Flanders, Belgium. Personality and Individual Differences, 166, 110220. https://doi.org/10.1016/j.paid.2020.110220

Cronbach, J. L. (1951). Coefficient alpha and the internal structure of tests. Psychometrika, 16, 297-334 https://link.springer.com/artic le/10.1007/BF02310555

Crowne, D. P., \& Marlowe, D. (1960). A new scale of social desirability independent of psychopathology. Journal of Consulting Psychology, 24(4), 349-354. https://doi.org/10.1037/h0047358

Damásio, B. F., \& Borsa, J. C. (2017). Manual de desenvolvimento de instrumentos psicológicos. Vetor.

DeVellis, R. F. (2016). Scale development: Theory and applications. (4a Ed.) Sage Publications.

Díaz, A., Soriano, J. F., \& Beleña, A. (2016). Perceived vulnerability to disease questionnaire: Factor structure, psychometric properties and gender differences. Personality and Individual Differences, 101, 42-49. https://doi.org/10.1016/j.paid.2016.05.036

Dimitrov, D. M. (2012). Statistical methods for validation of assessment scale data in counseling and related fields. American Counseling Association.

DiStefano, C., \& Morgan, G. B. (2014). A comparison of diagonal weighted least squares robust estimation techniques for ordinal data. Structural Equation Modeling, 21(3), 425-438. https://doi. org/10.1080/10705511.2014.915373

Dobriban, E. \& Owen, A.B (2019). Deterministic parallel analysis: an improved method for selecting factors and principal components. Journal of the Royal Statistical Society Series B, 81(1), 163-183. 10.1111/rssb.12301

Duncan, L. A., Schaller, M., \& Park, J. H. (2009). Perceived vulnerability to disease: Development and validation of a 15-item self-report instrument. Personality and Individual Differences, 47, 541-546. https://doi.org/10.1016/j.paid.2009.05.001

Faulkner, J., Schaller, M., Park, J. H., \& Duncan, L. A. (2004). Evolved disease-avoidance mechanisms and contemporary xenophobic attitudes. Group Processes \& Intergroup Relations, 7, 333-353. https://doi.org/10.1177/136843020404614

Ferguson, E., \& Daniel, E. (1995). The illness attitudes scale (IAS): A psychometric evaluation of a non-clinical population. Personality and Individual Differences, 18, 463-469. https://doi.org/10.1016/ 0191-8869(94)00186-V

Fukukawa, Y., Oda, R., Usami, H., \& Kawahito, J. (2014). Development of a Japanese version of the perceived vulnerability to disease scale. The Japanese journal of Psychology, 85, 188-195. https://doi.org/10.4992/jjpsy.85.13206
Garson, G. D. (2015). Structural equation modeling. Statistical Associates.

Green, E., Krings, F., Staerklé, C., Bangerter, A., Clémence, A., Wagner-Egger, P., \& Bornand, T. (2010). Keeping the vermin out: perceived disease threat and ideological orientations as predictors of exclusionary immigration attitudes. Journal of Community \& Applied Social Psychology, 20(4), 299-316. https:// doi.org/10.1002/casp.1037

Haidt, J., McCauley, C., \& Rozin, P. (1994). Individual differences in sensitivity to disgust: A scale sampling seven domains of disgust elicitors. Personality and Individual Differences, 16, 701-713. https://doi.org/10.1016/0191-8869(94)90212-7

Horn, J. L. (1965). A rationale and test for the number of factors in factor analysis. Psychometrika, 30(2), 179-185. https://doi.org/ 10.1007/BF02289447

Inhorn, M. C., \& Brown, P. J. (1990). The anthropology of infectious disease. Annual Review of Anthropology, 19, 89-117. https:// doi.org/10.1146/annurev.an.19.100190.000513

Jakobsen, J. C., Gluud, C., Wetterslev, J., \& Winkel, P. (2017). When and how multiple imputation should be used for handling missing data in randomised clinical trials - a practical guide with flowcharts. Medicine Research Methodology, 17(1), 1-10. https://doi.org/10.1186/s12874-017-0442-1

Kellner, R. (1986). Somatization and hypochondriasis. Praeger Publishers.

Li, C. H. (2016). Confirmatory factor analysis with ordinal data: Comparing robust maximum likelihood and diagonally weighted least squares. Behavioral Research Methods, 48(3), 936-949. https://doi.org/10.3758/s13428-015-0619-7

Magallares, A., Apodaca, M. J. F. R., \& Morales, J. F. (2017). Psychometric properties and criterion validity of the perceived vulnerability to disease scale (PVD) in the Spanish population. International Journal of Social Psychology, 32(1), 164-195. https://doi.org/10.1080/02134748.2016.1248025

Magallares, A., \& Morales, J. F. (2017). Physical disgust, germ aversion and antifat attitudes: The mediational effect of perceived controllability of weight. Anales de Psicología, 33(1), 1-6. https://doi.org/10.6018/analesps.33.1.224751

Makhanova, A., Miller, S. L., \& Maner, J. K. (2015). Germs and the out-group: Chronic and situational disease concerns affect intergroup categorization. Evolutionary Behavioral Sciences, 9(1), 8-19. https://doi.org/10.1037/ebs0000028

McCrae, R. R., Kurtz, J. E., Yamagata, S., \& Terracciano, A. (2010). Internal consistency, retest reliability, and their implications for personality scale validity. Personality and Social Psychology Review, 15(1), 28-50. https://doi.org/10.1177/1088868310366253

Miller, S. L., \& Maner, J. K. (2012). Overperceiving disease cues: The basic cognition of the behavioral immune system. Journal of Personality and Social Psychology, 102(6), 1198-1213. https:// doi.org/10.1037/a0027198

Murray, D. R., Jones, D. N., \& Schaller, M. (2013). Perceived threat of infectious disease and its implications for sexual attitudes. Personality and Individual Differences, 54, 103-108. https://doi.org/ 10.1016/j.paid.2012.08.021

Nunnally, J. C. (1978). Teoria psicométrica (2a ed.). McGraw-Hill.

Olatunji, B. O., Haidt, J., McKay, D., \& David, B. (2008). Core, animal reminder, and contamination disgust: Three kinds of disgust with distinct personality, behavioral, physiological, and clinical correlates. Journal of Research in Personality, 42(5), 1243-1259. https://doi.org/10.1016/j.jrp.2008.03.009

Pakpour, A. \& Griffiths, M. D. (2020). The fear of COVID-19 and its role in preventive behaviors. Journal of Concurrent Disorders, O(0), 1-16. http://irep.ntu.ac.uk/id/eprint/39561/1/1313636_Griff iths.pdf

Park, J. H., Faulkner, J., \& Schaller, M. (2003). Evolved disease-avoidance processes and contemporary anti-social behavior: Prejudicial 
attitudes and avoidance of people with physical disabilities. Journal of Nonverbal Behavior, 27, 65-87. https://doi.org/10.1023/A: 1023910408854

Park, J. H., Schaller, M., \& Crandall, C. S. (2007). Pathogen-avoidance mechanisms and the stigmatization of obese people. Evolution and Human Behavior, 28, 410-414. https://doi.org/10.1016/j. evolhumbehav.2007.05.008

Park, J. H., Van Leeuwen, F., \& Chochorelou, Y. (2013). Diseaseavoidance processes and stigmatization: Cues of substandard health arouse heightened discomfort with physical contact. Journal of Social Psychology, 153, 212-228. https://doi.org/10.1080/ 00224545.2012 .721812

Pasquali, L. (2012). Análise fatorial para pesquisadores. LabPam.

Pilowsky, I. (1967). Dimensions of hypochondriasis. The British Journal of Psychiatry, 113(494), 89-93. https://doi.org/10.1192/bjp. 113.494 .89

Primi, R. (2004). Avanços na interpretação de escalas com a aplicação da Teoria de Resposta ao Item. Avaliação Psicológica, 3(1), 53-58 http://pepsic.bvsalud.org/scielo.php?script=sci_arttext\& $\mathrm{pid}=$ S1677-04712004000100006\&lng $=\mathrm{pt} \& \ln \mathrm{g}=\mathrm{pt}$

Prokop, P., \& Fančovičová, J. (2013). Self-protection versus disease avoidance. Journal of Individual Differences, 34, 15-23. https:// doi.org/10.1027/1614-0001/a000092

Raykov, T. (1997). Estimation of composite reliability for congeneric measures. Applied Psychological Measurement, 21(2), 173-184. https://doi.org/10.1177/01466216970212006

Salkovskis, P. M., Rimes, K. A., Warwick, H. M. C., \& Clark, D. M. (2002). The health anxiety inventory: Development and validation of scales for the measurement of health anxiety and hypochondriasis. Psychological Medicine, 32, 843-853. https://doi.org/10. 1017/s0033291702005822

Santisi, G., Magnano, P., \& Scuderi, V. E. (2021). Food Neophobia and food disgust: The mediating role of perceived vulnerability to disease. Behavioral Sciences, 11(65), 1-13. https://doi.org/10. 3390/bs11050065

Segurado, A. C., Cassenote, A. J., \& Luna, E. A. (2016). Saúde nas metrópoles - Doenças infecciosas. Estudos Avançados, 30(86), 29-49. https://doi.org/10.1590/S0103-40142016.00100003

Silber, H., Roßmann, J., \& Gummer, T. (2018). When near means related: Evidence from three web survey experiments on interitem correlations in grid questions. International Journal of Social Research Methodology, 21, 275-288. https://doi.org/10.1080/ 13645579.2017.1381478

Silva, W., de Sampaio Brito, T. R., \& Pereira, C. R. (2020). COVID-19 anxiety scale (CAS): Development and psychometric properties. Current psychology (New Brunswick, N.J.), 1-10. Advance online publication. https://doi.org/10.1007/s12144-020-01195-0

Simpson, J. A., \& Gangestad, S. W. (1991). Individual differences in sociosexuality: Evidence for convergent and discriminant validity. Journal of Personality and Social Psychology, 60, 870-883. https://doi.org/10.1037//0022-3514.60.6.870

Stangier, U., Kananian, S., \& Schüller, J. (2021). Perceived vulnerability to disease, knowledge about COVID-19, and changes in preventive behavior during lockdown in a German convenience sample. Current psychology, 1-9. https://doi.org/10.1007/ s12144-021-01456-6.

Stewart, S. H., \& Watt, M. C. (2000). Illness attitudes scale dimensions and their associations with anxiety-related constructs in a nonclinical sample. Behavior Research Theory, 38(1), 83-99. https://doi.org/10.1016/s0005-7967(98)00207-1

Streiner, D. L., \& Kottner, J. (2014). Recommendations for reporting the results of studies of instrument and scale development and testing. Journal of Advanced Nursing, 70(9), 1970-1979. https:// doi.org/10.1111/jan.12402

Vala, J., Pereira, C. R., \& Costa-Lopes, R. (2009). Is the attribution of cultural differences to minorities an expression of racial prejudice? International Journal of Psychology, 44(1), 20-28. https:// doi.org/10.1080/00207590802057837

Vala, J., Pereira, C. R., Lima, M. E. O., \& Leyens, J.-P. (2012). Intergroup time bias and racialized social relations. Personality \& Social Psychology Bulletin, 38(4), 491-594. https://doi.org/10. 1177/0146167211429746

Valentini, F., \& Damásio, B. F. (2016). Variância Média Extraída e Confiabilidade Composta: Indicadores de Precisão. Psicologia: Teoria \& Pesquisa, 32(2), 1-17. https://doi.org/10.1590/0102$3772 \mathrm{e} 322225$

Viladrich, C., Angulo-brunet, A., \& Doval, E. (2017). A journey around alpha and omega to estimate internal consistency reliability. Annals of Psychology, 33, 755-782. 10.6018/analesps.33.3.268401

Wu, B.-P., \& Chang, L. (2012). The social impact of pathogen threat: How disease salience influences conformity. Personality and Individual Differences, 53(1), 50-54. https://doi.org/10.1016/j.paid. 2012.02.023

Yamada, Y., Xu, H., \& Sasaki, K. (2020). A dataset for the perceived vulnerability to disease scale in Japan before the spread of COVID-19. F1000Research, 9, 4(332). https://doi.org/10.12688/ f1000research.23713.2

Zhang, Z., \& Yuan, K.-H. (2018). Practical statistical power analysis using WebPower and $R$. ISDSA Press.

Publisher's Note Springer Nature remains neutral with regard to jurisdictional claims in published maps and institutional affiliations.

Emerson Araújo Do Bú Ph.D. Student in Social Psychology at the Faculty of Psychology, University of Lisbon. Research Assistant at the Institute of Social Sciences, University of Lisbon. He obtained a BA in Psychology at the Federal University of Campina Grande and a Master's degree in Social Psychology at the Federal University of Paraíba.

Maria Edna Silva de Alexandre Ph.D. Student in Social Psychology at the Federal University of Paraíba. She obtained a BA in Psychology at the Federal University of Campina Grande and a Master's degree in Social Psychology at the Federal University of Paraíba.

Alessandro Teixeira Rezende Ph.D. in Social Psychology. Professor of Psychology at the Faculdade de Integração do Sertão. He obtained a BA in Psychology and a Master's degree in Social Psychology at the Federal University of Paraíba.

Viviane Alves dos Santos Bezerra Ph.D. Student in Social Psychology at the Federal University of Paraíba. She obtained a BA in Psychology at the Federal University of Campina Grande and a Master's degree in Social Psychology at the Federal University of Paraíba. 